\title{
Analysis of Community-Based Poverty Reduction Agency and Civil Resources Development and Documentation Centre: Implications for Sustainable Poverty Alleviation in Central Zone of Ebonyi State Nigeria
}

\author{
S.O Eze* and E. A. Onwubuya** \\ *Dept. of Agric Econs Management and Extension \\ Ebonyi State University, P.M.B 53 Abakaliki Ebonyi State \\ E-mail: simoeze 2004@yahoo.co.uk \\ **Dept of Agricultural Extension \\ University of Nigeria, Nsukka
}

\begin{abstract}
This study analyzed community-Based Poverty Reduction Agency (CPRA) and Civil Resources Development and Documentation Centres (CIRDDC) and highlighted implications for sustainable poverty alleviation in central zone of Ebonyi state, Nigeria. Two hundred and forty randomly selected participants in poverty alleviation activities of both CPRA and CIRDDC constituted the sample size for the study, while an interview schedule for the participants as beneficiaries was employed for data collection. Both descriptive statistics namely; percentages and mean scores as well as a group t-test were adopted in data analysis. The findings revealed that majority (60.71\%) of CPRA compared with $48.88 \%$ of CIRDDC beneficiaries were males, while only $34.68 \%$ of CIRDDC compared with majority (58.63\%) of CPRA beneficiaries were married. Large (53.38\%) numbers of CPRA compared with $47.54 \%$ of CIRDDC were within the age range of $30-59$ years, while majority (63.07\%) of them under CIRDDC compared with $56.36 \%$ of CPRA belonged to 6-15 member household. Furthermore, only $26.79 \%$ of CPRA compared with $26.56 \%$ of CIRDDC beneficiaries had WASC/SSCE/GCE O/L, while 25\% of CIRDDC compared with $28.57 \%$ of CPRA were either traders or artisans. Majority (69.64\%) of CPRA compared with $65.63 \%$ of CIRDDC beneficiaries reported estimated annual saving income of N10,000-N30, 000.00. Differences existed between CPRA and CIRDDC in all their poverty alleviation projects and dimensions of strategies employed by the agencies. Above all, the CIRDDC focused on group formation and orientation and had higher socio-economic impacts on their beneficiaries than the CPRA. The study recommends restructuring the CPRA and CIRDDC as well as streamlining their activities in line with workable public-private partnership to work with other rural-oriented organizations. The conclusion is that sustainable poverty alleviation in the central zone of Ebonyi state, Nigeria depends on the extent issues raised as implication in harmonizing the operations of CPRA and CIRDDC can be addressed and sustained.
\end{abstract}


Journal of Agricultural Extension

Vol. 13 (1) June, 2009

\section{INTRODUCTION}

Poverty has been estimated to engulf about $1.3 \mathrm{~m}$ population worldwide (Oladipo, 1999). According to Elumilade and Asaola, (2006) Africa is predominantly populated by poor people and good proportion of the African poor are Nigerians. Geometrical progression in the incidences of poverty has been reported in Nigeria between 1980 and 1985 as well as 1992 and 1996 against Government efforts on poverty alleviation (MDGR, 2004).

Some specific Government supported programmes aimed at poverty alleviation in Nigeria include; Agricultural Development Programme, ADP (1975), Directorate of Food, Road and Rural Infrastructure, DFRRI (1986), and family Economic Advancement Programme, FEAP (1998). Others include, National Fadama Development Project, NFDP (1992), Nigeria Agricultural Co-operative and Rural Development Bank, NACRDB (2000) and Communitybased poverty Reduction Agency, CPRA (2003). In addition, some international private and non-governmental organizations namely; United Nations Development Programme (UNDP), Micro-finance Banks (MFB), and civil Resources Development and Documentation centre (CIRDDC) have implemented poverty alleviation projects to the people simultaneously. More over, CPRA operates under civil service framework and it is somewhat beset with civil service beaucratic control (Badru, 2002). On the part of CIRDDS the structure reflected a typical NGO, which permits diverse population participation especially those who can afford the cost of their services mostly provided on cost-sharing and user pay basis. Accordingly the CIRDDC is structured to focus on effects of poverty on specific relatively small ecological areas and social groups who are not exempted from the programmes of CPRA. However, in agricultural extension approach to rural development and poverty reduction, governmental and nongovernmental organization have often co-existed in order to achieve the desired results.

In Ebonyi state of Nigeria both CPRA and CIRDDC are the most prominent government supported and non-governmental poverty reduction agencies which implement programmes simultaneously to the beneficiaries. The CPRA is funded by the government, while CIRDDC is funded by donor agencies and interest organizations. However, both of them employ independent structures and modes of operation in pursuing their specific objectives to the same target beneficiaries. As a government funded agency, CPRA operated a national and state coordinating offices, while linking up with community implementation committees and CIRDDC implemented poverty alleviation projects direct to the local/benefiting communities. Over the years, little progress has been made in achieving poverty alleviation in Ebonyi state, Nigeria despite the huge human, material and financial support and investment. With obvious dwindling in fund allocation secondary to global economic recession and uncompromising urge and intents in poverty alleviation, there is need for strengthened public-private partnership in necessary projects in order to achieve the desired sustainability in poverty alleviation.

One major assumption behind simultaneous operations of Government funded CPRA and NGO such as CIRDDC in poverty alleviation activities is that development efforts could be enhanced more meaningfully through joint efforts of the two agencies. Moreover, in Ebonyi state involvement of NGO such as CIRDDC as a distinct development agency could be seen as a deliberate private initiative to improve development activities and contribute to poverty alleviation needs of Ebonyi people. However, in a period of competitive demand on beneficiaries time and other relevant but scarce resources as well as efforts of Government to allocate scarce fund both the beneficiaries and policy makers would be forced to make critical choice between investment alternatives based on proper analysis. Successful poverty alleviation no doubt, must involve projects and strategies with notable improvements on the sound economic conditions of beneficiaries as measures to detect extent of achievements. What are the different poverty alleviation projects, executed by CPRA and CIRDDC in central zone of Ebonyi state, Nigeria? 
What strategies have been employed by CIRDDC and CPRA in their separate contacts with the people? Previous research reports by Masoni (1985), Elumilade and Asaola (2006) have independently investigated the roles of public and NGOs in poverty alleviation. However, there is paucity of information on analysis of public and private agencies especially CPRA and CIRDDC visa vis their socio-economic impacts on beneficiaries as they relate to poverty alleviation in central zone of Ebonyi state, Nigeria. What are the socio-economic impacts of the beneficiaries that could be attributable to CPRA or CIRDDC? What specific issues constitute implications for streamlining the activities of CIRDOC and CPRA in order to achieve the desired public-private partnership and participation for overall sustainability in poverty alleviation in central zone of Ebonyi state, Nigeria?

The overall purpose of this study was to analyse the activities of CPRA and CIRDDC and highlight their implications for public-private partnership and sustainable poverty alleviation in the central zone of Ebonyi state, Nigeria. Specifically the objectives include to; i). describe the socio-economic characteristics of beneficiaries, ii). analyze poverty alleviation projects executed by the CPRA and CIRDDC and iii). analyze strategies employed by the agencies in contacting beneficiaries. Others include to, iv). analyze the socio-economic impacts of CIRDDC and CPRA on the beneficiaries and highlight their implications for sustainable poverty alleviation in the central zone of Ebonyi state, Nigeria.

\section{METHODOLOGY}

The study covered Ebonyi central zone made up of four Local Government Areas (LGAs) namely; Ezza North, Ezza South, Ikwo and Ishielu. All farmers and non-farmers within the zone constituted the population for the study. Both purposive and multi-stage sampling techniques were employed. Two local Government Areas namely; Ezza south and Ikwo were purposively selected basically because of the proximity to one another and the intensity of poverty alleviation projects in the LGA hence their representative of active poor in the zone. Four communities each from the LGAs selected were purposively involved basically because of intensity of the poverty alleviation activities of both the CPRA and CIRDDC in the communities. The communities include Ameka, Amudo, Idembia, and Ezzaama for Ezza south and Inyimagu, Igbudu, Ekpa-omaka and Echara for Ikwo LGA. Three villages from each of the selected communities were randomly involved, while 10 beneficiaries of the poverty alleviation agencies from each of the villages involved were randomly selected. Thus a total of 240 respondents made up of 30 per community selected and 120 per local Government Area involved constituted the sample size for the study.

An interview schedule for rural people was developed, validated and employed for data collection. The interview schedule was organized in sections and reflected issues on personal characteristics of the beneficiaries under CIRDDC and CPRA, poverty alleviation projects and strategies as well as socio-economic impacts of the agencies on beneficiaries. A five point Likert type scale was employed and values assigned to each options in data collection and to measure the magnitude of the responses namely: strongly Agree $(S A=5)$; Agree $(A G=4)$; Undecided (UD = 3); Disagree ( $D A=2)$ and strongly Disagree $(S D=1)$. The mean value was determined as 3.0 and employed as basis in discussing objective 4 on socio-economic impacts on the beneficiaries. Descriptive statistics namely; percentages was employed in analyzing objectives 1, and 3 while objective 2 was analyzed using a group t-test. 
Journal of Agricultural Extension

Vol. 13 (1) June, 2009

\section{RESULTS AND DISCUSSION}

\section{Socio-economic Characteristics of beneficiaries of Poverty alleviation projects under} CPRA and CIRDDC

Data in Table 1 reveal that majority $(60.71 \%)$ of CPRA beneficiaries compared with $46.88 \%$ of CIRDDC were males, while majority $(58.63 \%)$ of CPRA compared with $34.68 \%$ of CIRDDC were married. The foregoing indicates that CPRA involved more men in their programmes than the CPRDDC who targeted more married females (59.13\%) than the CPRA. In terms of age majority $(72.03 \%)$ of CPRA compared with $67.21 \%$ of CIRDDC beneficiaries were 21-49 years, while only $16.4 \%$ of CIRDDC compared with $14.42 \%$ of CPRA beneficiaries were 50 years and above. Thus both CIRDDC and CPRA targeted adult beneficiaries within the active age group in their poverty reduction projects. 
TABLE 1: Percentage Distribution of the socio-economic characteristics of beneficiaries under CPRA and CIRDDC

\begin{tabular}{|c|c|c|c|c|}
\hline \multirow{2}{*}{ Variable } & \multicolumn{2}{|l|}{ CPRA } & \multicolumn{2}{|c|}{ CIRDDC } \\
\hline & Frequency & $\%$ & Frequency & $\%$ \\
\hline \multicolumn{5}{|l|}{ Sex } \\
\hline Male & 68 & 60.71 & 60 & 46.88 \\
\hline Female & 44 & 39.29 & 68 & 59.13 \\
\hline \multicolumn{5}{|l|}{ Marital status } \\
\hline Single & 32 & 27.59 & 54 & 43.55 \\
\hline Married & 68 & 58.63 & 43 & 34.68 \\
\hline Divorced & 10 & 8.62 & 14 & 11.29 \\
\hline Widowed & 6 & 5.17 & 13 & 10.48 \\
\hline \multicolumn{5}{|l|}{ Mean Age (Yrs) } \\
\hline Young (25) & 48 & 40.68 & 56 & 45.90 \\
\hline Middle (40) & 53 & 44.91 & 46 & 37.70 \\
\hline Old $(55)$ & 10 & 8.47 & 12 & 9.84 \\
\hline \multicolumn{5}{|c|}{ Mean Household size } \\
\hline Small (3) & 32 & 29.10 & 26 & 20 \\
\hline Medium (8) & 42 & 38.18 & 48 & 36.92 \\
\hline Large (13) & 20 & 18.18 & 34 & 26.15 \\
\hline \multicolumn{5}{|l|}{ Education level } \\
\hline No formal education & 8 & 7.14 & 16 & 12.5 \\
\hline Primary & 26 & 23.21 & 30 & 23.44 \\
\hline WASC/SSCE/GCE & 30 & 26.79 & 34 & 26.56 \\
\hline OND/NCE & 32 & 28.57 & 28 & 21.88 \\
\hline HND/BA/BED/BS.C & 12 & 18.71 & 20 & 15.63 \\
\hline MED/MA/MSC/MBA & 4 & 3.57 & - & - \\
\hline \multicolumn{5}{|l|}{ Occupation } \\
\hline Part-time farming & 28 & 25 & 44 & 34.38 \\
\hline Fulltime farming & 24 & 21.43 & 32 & 25 \\
\hline Trading & 18 & 16.07 & 16 & 12.5 \\
\hline Civil servant & 28 & 25 & 20 & 15.63 \\
\hline Artisan & 14 & 12.5 & 16 & 12.5 \\
\hline \multicolumn{5}{|c|}{ Annual savings income } \\
\hline $10,000-20,000$ & 52 & 46.43 & 60 & 46.88 \\
\hline $21,000-30,000$ & 26 & 23.21 & 24 & 18.75 \\
\hline $31,000-40,000$ & 14 & 12.5 & 18 & 14.06 \\
\hline $41,000-60,000$ & 12 & 10.71 & 14 & 10.94 \\
\hline 61,000 and above & 8 & 7.14 & 12 & 9.38 \\
\hline
\end{tabular}

Source: Field survey, 2008

Table 1 also revealed that majority (63.07\%) of CIRDDC compared with $56.36 \%$ of CPRA beneficiaries had household size of 6-15 members, while $48.44 \%$ of them under CIRDDC compared with $55.36 \%$ of CPRA had at least secondary school. Household size has social and economic implications to household demands and determines the poverty level of a population (Dauda, 2002) Thus the larger the household membership, the higher the demands and higher the propensity to poverty. Also the study suggests that the two poverty alleviation agencies in Ebonyi central zone targeted beneficiaries with necessary educational qualification to participate 
in poverty reduction projects. The study therefore agrees with Blum (1991) and Madukwe (1995) who viewed education as a facilitating factor to any development programmes. In terms of occupation, majority (59.38\%) of CIRDDC compared with $46.43 \%$ of CPRA beneficiaries were either part-time or full-time farmers, while $53.57 \%$ of CPRA beneficiaries compared with 40.63 $\%$ of CIRDDC beneficiaries were either traders, civil servants or artisans. In addition, majority (82.14\%) of CPRA beneficiaries compared with $79.69 \%$ of those under CIRDDC reported their estimated annual saving income of N10, 000.00- N40,000.00. Only $20.32 \%$ of CIRDDC compared with $17.85 \%$ under CPRA reported estimated annual income of either N41, 000.00 N61, 000.00 or above. This study therefore indicates that both CPRA and CIRDDC focused their poverty alleviation projects on the active poor groups in the central zone of Ebonyi State.

\section{Poverty Alleviation Projects under CPRA and CIRDDC}

Data in Table 2 indicate differences between the CPRA and CIRDDC in their implemented poverty alleviation projects in various communities in the central zone of Ebonyi state. Specific among these poverty alleviation projects include; water boreholes $(t=4.5)$, health centre $(t=$ $2.52)$ and roads project $(t=3.05)$.

TABLE 2: Differences in the poverty alleviation projects between CPRA and CIRDDC

\begin{tabular}{lccc}
\hline Poverty Alleviation project & $\begin{array}{c}\text { CPRA } \\
\text { Min = 1 }\end{array}$ & $\begin{array}{c}\text { CIRDDC } \\
\text { Min = 1 }\end{array}$ & t-cal \\
& $\operatorname{MAX}=5$ & MAX = 5 & \\
& $\overline{\mathbf{X}}=\mathbf{3 . 0}$ & $\overline{\mathbf{X}}=\mathbf{3 . 0}$ & \\
\hline Water scheme project (Borehole) & $2.33(0.643)$ & $2.63(0.208)$ & $4.496^{*}$ \\
Health projects & $3.4(0.652)$ & $3.16(0.702)$ & $2.521^{*}$ \\
Road network & $3.95(0.212)$ & $2.6(0.707)$ & $3.051^{*}$ \\
Rural electrification infrastructure & $3.6(0.202)$ & $2.3(0.301)$ & $2.169^{*}$ \\
Small business enterprise & $2.76(0.537)$ & $3.14(0.462)$ & $2.226^{*}$ \\
Skill acquisition centers & $2.61(0.436)$ & $2.42(0.341)$ & $3.3^{*}$ \\
Adult/Non-formal literacy programme & $2.98(0.607)$ & $2.88(0.444)$ & $3.222^{*}$ \\
Small scale crops/livestock farm projects & $2.73(0.25)$ & $2.7(0.627)$ & $2.566^{*}$ \\
\hline
\end{tabular}

* $P<0.05 ; d f=238$

+ Figures in parenthesis represent standard deviation

Table 2 further reveals differences between the two organizations in rural electrification infrastructure $(t=2.17)$, small businesses enterprise $(t=2.23)$, skill acquisition centers $(t=3.3)$ and non-formal/adult education project $(t=3.22)$ and in small-scale crops/livestock farming as poverty alleviation projects $(\mathrm{t}=2.57)$. The foregoing analysis reveals that under water borehole projects CIRDDC $(\bar{x}=2.63)$ performed better than CPRA $(\bar{x}=2.33)$, while CPRA made better achievements in health centre projects $(\bar{x}=3.4)$ and Road project $(\bar{x}=3.95)$ than CIRDDC with mean scores of 3.16 and 2.6 respectively. Furthermore, CIRDDC $(\bar{x}=3.14)$ did better than CPRA $(\bar{x}=2.76)$ in small business enterprise, while CPRA $(\bar{x}=2.61)$ performed 
better than CIRDDC ( $\bar{x}=2.42)$ in skill acquisition centers. The CIRDDC was limited in nonformal/adult education $(\bar{x}=2.88)$ compared with CPRA $(\bar{x}=2.98)$ and small-scale crops/livestock farming $(\bar{x}=2.7)$ compared with CPRA $(\bar{x}=2.73)$. The foregoing analysis provides areas of discrepancies and comparative advantages in implementing sustainable poverty alleviation projects to beneficiaries in the central zone of Ebonyi state, Nigeria. These areas of discrepancies indicate critical policy issues for consideration in order to achieve the desired harmonization between the CPRA and CIRDDC in order to achieve the desired sustainability in poverty alleviation in central zone of Ebonyi state, Nigeria.

\section{Poverty Alleviation Strategies Employed by CPRA and CIRDDC}

Data in Table 3 indicate beneficiaries perception of various poverty alleviation strategies employed by CPRA and CIRDDC. Specific among the strategies include; Group Contacts with $24.07 \%$ under CPRA compared with CIRDDC (20.99\%), group formation and orientation with $18.52 \%$ under CIRDDC compared with CPRA (8.02\%). Other specific strategies employed for poverty alleviation include; participant demonstration on individual basis with $8.64 \%$ under CIRDDC compared with CPRA (11.32\%) and involvement of resource persons with $17.28 \%$ under CPRA compared with CIRDDC (22.22\%). The beneficiaries reported strategies such as motivation for self help with CIRDDC (18.52\%) compared with CPRA (23.46\%) and skill training with CIRDDC (11.11\%) compared with CPRA (4.81\%). Group contact no doubt, is crucial for purposes of multiplier effects and it is imperative for a viable agency beneficiaries relationships. The result indicates that CPRA probably based their contacts on active poverty groups while CIRDDC appeared to emphasis group orientation for purpose of group permanency and negotiation of group interests in poverty alleviation projects than the CPRA. The CPRA appeared to emphasis development of necessary competencies by encouraging individual participant demonstration and also encouraged self-help projects among the beneficiaries as against the CIRDDC, which involved resource persons in their poverty alleviation more than the CPRA.

TABLE 3: Beneficiaries Perception of Poverty Alleviation strategies between CPRA and CIRDC

\begin{tabular}{lcc}
\hline \multicolumn{1}{c}{ Poverty alleviation strategies } & CPRA (\%) & CIRDDC (\%) \\
\hline Group contacts & 24.07 & 20.99 \\
Demonstration with individual participants & 12.35 & 8.64 \\
Involvement of Resource persons & 17.28 & 22.22 \\
Motivation for self help projects & 23.46 & 18.52 \\
Formation and orientation in groups & 8.02 & 18.52 \\
Skill/Apprenticeship training & 14.81 & 11.11 \\
Capacity building & 12.19 & 11.17 \\
Provision of rural infrastructure & 16.63 & 14.67 \\
Provision of subsidized farm inputs & 14.54 & 13.03 \\
Use of Radio/TV broadcast & 16.1 & 14.12 \\
\hline
\end{tabular}

Multiple responses 
Table 3 revealed other poverty alleviation strategies employed in central zone of Ebonyi state to include; capacity building with $12.19 \%$ under CPRA compared with CIRDDC (11.17\%) and provision of rural infrastructure with $14.67 \%$ under CIRDDC compared with CPRA (16.63\%). This study therefore, agrees with Daudu (2002) who noted that education and provision of basic infrastructures such as electricity, road network, transportation and health facilities are necessary strategies for decent living and poverty alleviation in Nigeria. This situation requires streamlining the efforts of CPRA and CIRDDC based on their organizational attributes in order to meet the infrastructural needs of the poor in central zone of Ebonyi state. Moreover, the result indicates that the CPRA (14.54\%) differed from the CIRDDC (13.03\%) in dimensions of providing subsidized farm inputs and employed use of Radio/TV broadcast with CIRDDC $(14.12 \%)$ compared with CPRA $(16.1 \%)$ in reaching the beneficiaries. Thus both CPRA and CIRDDC agreed with Idachaba (1985) who noted strategies focusing on farm occupation as critical measure towards bolstering the income base of farmers and poverty alleviation among vulnerable groups in Nigeria.

\section{Socio-Economic Impacts OF CPRA and CIRDDC on their Beneficiaries}

Data in Table 4 indicate that both CPRA and CIRDDC made significant socio-economic impacts on their beneficiaries.

TABLE 4: Mean Distribution of Beneficiaries according to socio-economic impacts under CPRA and CIRDDC

\begin{tabular}{lcc}
\hline \multicolumn{1}{c}{ Socio-economic issues } & CPRA (Max = 5) & CIRDDC (Max = 5) \\
\hline Improved income generation & 3.8 & 3.3 \\
Increased school enrolment of children/adult literacy & 3.8 & 3.2 \\
Accessibility to modern health care & 3.9 & 3.3 \\
Awareness on HIVIAIDS & 2.9 & 4.5 \\
Improved environmental condition & 3.7 & 3.1 \\
Acquisition of household assets & 3.8 & 3.6 \\
Better nutritional status & 4.0 & 3.6 \\
Technical skill competencies & 3.3 & 3.0 \\
Accessibility to rural infrastructure & 3.3 & 3.7 \\
Political awareness (Democracy and good & 2.2 & 4.6 \\
governance) & & \\
Membership of rural organizations and participation & 3.5 & 4.3 \\
in self help project & & \\
Freedom from superstition & 2.2 & 3.8 \\
\hline
\end{tabular}

Source: Field survey, 2008

The CPRA and CIRDDC made comparable socio-economic impacts on their beneficiaries in the areas of income generation, enrolment of children in schools/adult literacy and accessibility to modern health care services. Table 4 indicates that, the CIRDDC beneficiaries made comparative socio-economic achievements over the CPRA in areas of awareness on HIVIAIDS ( $\bar{x}=4.5)$, political awareness $(\bar{x}=4.6)$ and freedom from superstition $(\bar{x}=3.8)$. These areas of discrepancies in socio-economic achievements among the beneficiaries constitute critical issues for policy consideration in order to achieve the required comprehension and overall sustainability in poverty alleviation in the central zone of Ebonyi state, Nigeria. 


\section{Policy Implications for Sustainable Poverty Alleviation}

There is a consensus from the study that both poverty alleviation agencies of CPRA and CIRDDC can be accredited with remarkable achievements in terms of operational targets and set goals. However, consistency in operations of CPRA and CIRDDC with national poverty alleviation objectives and millennium development goals demands conscientious efforts to harmonize their strategies as prominent public and private agencies in central zone of Ebonyi state, Nigeria. Harmonization in the strategies for poverty alleviation based on established comparative advantages is required to achieve sustainability between the CPRA and CIRDDC in central zone of Ebonyi state, Nigeria. Based on the analysis, the CPRA should utilize endearing civil service framework to provide quality staff. The envisaged personnel can employ strategies of co-ordination, guidance, monitoring and supervision as well as direction and control in linking with CIRDDC in implementing poverty alleviation projects in central zone of Ebonyi state Nigeria. The co-ordinating roles of CPRA could be facilitated by utilizing the limited bureaucratic organization of the CIRDDC in stimulating participation among beneficiaries for need determination and embarking on self-help projects. This can be achieved by employing the informal organizational structure of the CIRDDC into critical strategy towards stimulating rural leadership and improving management of available resources.

Also the study revealed that CPRA performed better than CIRDDC in using strategies such as group contacts, motivation for self help projects, provision of rural infrastructure and use of Radio/TV broadcast. The CPRA therefore should take complete responsibility for contacting beneficiaries in groups, providing rural leadership and facilitation training in order to involve the groups in need determination, project designs and implementation of poverty alleviation projects. The current situation of appointing facilitators among rural poverty groups without definite criteria may need to be overhauled to focus attention on categorization of beneficiaries according to their preferred poverty alleviation projects for meaningful participation and easy coordination on the part of CPRA. Thus the CPRA could employ group formation and orientation arrangement under the CIRDDC as necessary area of co-operation in mobilizing the beneficiaries for group decisions. These issues are needed to encourage the emerging leadership and advocacy roles of groups in negotiating their interest on relevant poverty alleviation projects as measures to achieve sustainability in central zone of Ebonyi state. The CPRA should therefore relinquish the responsibility of group formation and primary function of group orientation to the CIRDDC while concentrating efforts on group training, motivation and provide input on resource persons in poverty alleviation facilitation training.

The foregoing has implications for improved staff training under the CPRA in group dynamics in order to achieve their efficiency in working with rural groups. This situation implicates the roles of CIRDDC in contributing towards staff and beneficiaries training in terms of providing some financial and logistic supports as her private partnership contribution in poverty alleviation. Moreover, the envisaged staff motivation through training and improved group contacts of beneficiaries requires that more staff will be needed under CPRA in order to contend with the emerging increases in the poverty alleviation beneficiaries. This requires either increasing the numerical staff strength under the CPRA or increasing the workload of available staff of the agency and related rural-oriented organizations such as the Agricultural Development Programme (ADP) and Local Government Areas. Either measure or both are necessary and requires improved funding and budgetary allocations on the part of Ebonyi state Government to CPRA and the ADP. The Government could equally re-orientate and retrain community development officers of L.G.A as part of their supporting and linkage strategies for poverty alleviation in the state. The linkage activities can be monitored, supervised and co-ordinated by the state ministry for Economic Empowerment and Poverty Reduction. By so doing relevant 


\section{Journal of Agricultural Extension}

Vol. 13 (1) June, 2009

agencies could be energized to establish workable structure which can stimulate beneficiaries and regulate their participation for sustainable poverty alleviation in central zone of Ebonyi state, Nigeria.

\section{CONCLUSION}

The study analyzed CPRA and CIRDDC and highlighted implications for sustainable poverty alleviation in central zone of Ebonyi state. This study was based on the premise that meaningful co-existence of CPRA and CIRDDC and their contribution towards the beneficiaries demands comparative analysis of their projects and poverty alleviation strategies to eliminate duplication of efforts unhealthy competition and confusion among beneficiaries and achieve sustainability in their operations. Considering their unique organizational features and differences in their specific poverty alleviation projects and strategies, the study recommended restructuring CPRA and CIRDDC as poverty alleviation agencies in order to harmonize their functions and funding support to the CPRA. In addition a workable structure need to be established between the prominent poverty alleviation agencies and other rural-oriented organizations like the ADP and LGAs while their activities should be co-ordinated by the ministry of Economic Empowerment and Poverty Reduction in Ebonyi state of Nigeria. The conclusion is that sustainable poverty alleviation in central zone of Ebonyi state, Nigeria depends on the extent the issues raised as implications and necessary in streamlining the operations of CPRA and CIRDDC can be addressed and sustained.

\section{REFERENCES}

Badru, A.F, (2002). Rural Poverty Amelioration - A key to sustainable Development in Nigeria; In: A.A. Jibowo (ed.). Nigeria journal of Rural Sociology; Nigerian Rural Sociological Association; Vol. 4, No. 1; special edition, December.

Blum, A; (1991). "What can be learned from a comparism of the Agricultural Knowledge system? The case of the Netherlands and Israel". Agricultural Ecosystem and Environment; 33, PP 325-339.

Daudu, R.O.S; (2002). Rural Poverty in Nigeria: Characteristics, Dimensions and Trends; In: A. A. Jibowo (ed). Nigerian Journal of Rural Sociology; Nigerian Rural Sociological Association; Vol. 4; No. 1; special edition, December.

Elumilade, O.O. and T.O. Asaola, (2006). Appraising Institutional Framework for poverty Alleviation Programmes in Nigeria; International Research Journal of Finance and Economic; Ewo Journals publishers, Inc.

Idachaba, F.S; (1985). "Rural Development in Nigeria". Foundations of sustainable economic recovery" Faculty lecture, Faculty of Agriculture, OAU, lle Ife pp. 16-17.

Madukwe, M.C. (1995). Agricultural Extension System and Strategies in Nigeria's Rural Development; In: E.C. Eboh, C.U. Okoye; and d. Ayidi (eds) Rural Development in Nigeria: Concepts, Processes and prospects; Enugu; Auto-century Publishing company; Pp. 314-320.

Masoni, U. (1985). Non-governmental Origination and Development; Finance and Development; World Bank. 
MDGR (2004). Millennium Development Goal Report; Eradicating extreme poverty and hunger in Nigeria; Pp. 7-14.

Oladipo, E. (1999). "Poverty alleviation as Imperative for sustainable Human Development", A paper presented on behalf of UNDP at the occasion marking the international day for Eradication of poverty (IDEP) 